\title{
Indigenous Knowledge Systems Discourse and Inclusionality: An Afro-centric Quest for Recognition in a Globalised World
}

\author{
Munyaradzi Felix Murove \\ Murovem@ukzn.ac.za
}

\begin{abstract}
The main goal of this essay is to argue that in a multicultural and globalised world, the indigenisation of knowledge production has to be pursued in a way that demonstrates an element of inclusivity. To achieve this goal this article's structure has three foci. Firstly, it is argued that the indigenisation of knowledge must be pursued under the presumption of a recognition that all knowledge is cultural or context specific to some degree. As such, the multicultural nature and plurality of knowledge systems formations should be acknowledged, as well as the fact that all knowledge production includes an aspect of the indigenisation of knowledge. Secondly, against this broader background, the argument for the indigenisation of knowledge in Africa goes hand-in-hand with the promotion of the intellectualisation of knowledge that is often regarded by Western scholarship as 'primitive', and thus redundant, in the face of modernity. This, however, is not only a universal for the production of all knowledge(s), but also foundational to all knowledge development, and should be recognised as such. Finally, given the plurality of knowledge formations, and the African celebration and development of its own knowledge formations, the quest for the indigenisation and intellectualisation of knowledge in African context, should be seen as a quest for the inclusionary appreciation of a multiplicity of global knowledges, whereby all knowledge is understood as context specific to some degree, and contributing to both local and general human wellbeing. This latter perspective implies a deliberately ethical stance, to the effect that in a globalised and multicultural world, no
\end{abstract}


knowledge system should be privileged as superior to any other knowledge system, and none, regarded as inferior.

Keywords: Indigenisation, knowledge, ethnicity, recognition, Africa, ethics, context, anthropology, recognition, multiculturalism, globalisation, inclusionnality

\section{Introduction}

In contemporary Africa south of the Sahara, the discourse of indigenisation has given impetus to the intellectualisation, and promotion of the study and development of African indigenous knowledge systems, across all the disciplines in the humanities and the natural sciences. This trend has impacted many systems across many regions in Africa, as well as in southern Africa, and is, for instance, evident in the fact that studies or research projects that are based on, or involve indigenous knowledge systems, are receiving preferential funding treatment as compared to those that are based on traditional Western knowledge systems. Yet, the precise argument for this phenomenon, has not been clarified sufficiently, and this article, aims to provide some perspectives on this hiatus.

Previously, knowledge systems of the colonizing powers, imposed themselves on the colonised as the only legitimate knowledge to the exclusion of the knowledge systems of the colonised. On the one hand, the colonial operationalising of these knowledge systems aimed at both the alienation of Africans from their own knowledges, existential realities, and traditions, as well as, the integration of the few into the colonial and colonising apparatuses. On the other hand, it prevented Africans from intellectualising and indigenising the knowledge(s) they encountered, on their own terms, and for their own purposes. This has led to the fact - as recognised by many postcolonial scholars regardless of their discipline orientation - that Africans in the postcolony have experienced the current dominant knowledge systems that have impacted and dominated the African epistemic terrain, as continuing to remain Eurocentric, and not African. Moreover, African leaders, scholars and academics have realised that much of what Africans know about themselves, has predominantly come from the Western world because of the history of colonialism. It is not rooted in the indigenous knowledges, and 
indigenous self-understandings. It is in the face of the existential as well as knowledge development challenges that this multi-faceted phenomenon has brought about, that African leaders and scholars have engaged African-focused knowledge development and knowledge production, or, in short, indigenous knowledge systems intellectualisation. For Africans, this matter has also become an ethical issue that thrives mainly on contemporary African politics of identity, and development, within a globalising world.

Further, if the end of both direct, and indirect colonisation brought about commitment to engage the indigenisation and production of knowledge, it also gave rise to the recognition of the reality of the plurality of cultural experiences, and therefore knowledge production. The pursuit of indigenous knowledge systems and the intellectualisation of indigenous knowledges, and knowledge production, thus, go hand in hand with the realisation that the world is composed of different cultures and different modes of being in the world. This means that the recognition of the world's existential realities of multiculturalism, also means an acknowledgement of the reality of pluralism in the realm of knowledge. This multicultural perspective is important, because it also means that the pursuit of indigenous knowledge systems intellectualisaton, should be understood as a quest for recognition in a world that has come to mostly accept the realities of multiculturalilsm. The indigenisation of knowledge through the pursuit of indigenous knowledge systems, then, do not only aim at correcting misperceptions that were created by Western scholars about African societies, especially during the time of colonisation. It also aims at displacing erroneous conceptions of notions of objectivity and neutrality in knowledge production, and the grounding of knowledge within African existential realities of self-understanding, and self-actualisation. Indigenous knowledge systems discourse, recognises that knowledge intellectualisation, and knowledge production, should not be divorced from contextual, nor cultural inclinations or experiences.

Finally, the main concern of this article is to put an argument forward for the inclusive nature of knowledge production. In a globalised and multicultural world, when knowledge is produced from multiple sites and from within multiple ethnicities, authentic knowledge production, is both multicultural and multi-ethnic. The logical deduction here is that, if all knowledge is multi-ethnic, knowledge as such, is inclusive of multiple ethnically-founded knowledges.

For this argument, the article is structured as follows: The first section 
argues that the indigenisation of knowledge through the pursuit of indigenous knowledge systems intellectualisation and knowledge production, implies that authentic knowledge should be culturally contextual in the sense that it should be appreciative of (ethnic) existential life experiences. In the second section it is argued that the debate on the indigenisation of knowledge and the global receptivity of indigenous knowledge systems intellectualisation, has the recognition of the indigenous knowledge systems as foundation. This view counters erroneous Eurocentric understandings of knowledge. In the last section, whilst the indigenisation of knowledge implies that knowledge is always ethnic to some degree, the argument here is that in a world that has come to recognise the reality of multiculturalism, the quest for indigenisation should be understood as a quest for inclusionary instead of exclusionary knowledge production practices. It is argued that whilst there is the reality of cultural diversity, sometimes there is a strong element of cultural convergence in our human experiences.

\section{Indigenisation of Knowledge as Recognition of Context Specificity of Knowledge}

During colonialism, the gathering, production, and dissemination of indigenous knowledge by anthropologists and missionaries, served as information for purposes of colonisation, and more generally, the promotion of colonising agendas. It is also well-known that all knowledge so produced, aimed at being responsive to academic developments and problematisations at home in the colonising countries. As such, if disseminated in the colonised context, it meant that the knowledge itself was distorted. Our current pursuit of indigenous knowledge systems development in Africa, is aimed to not only counter this trend in neo-colonial terms, but to produce knowledge that is relevant to the cultural contexts in which it is generated and disseminated. In this regard, there is a realisation among academics that knowledge production should link to the experiential world of indigenous communities, whereby social and cultural contexts play an academically indispensable role in the formation of discourses. For instance, there is a global consciousness among academics that terms used and examples generated with regard to particular phenomena in knowledge production, should be determined by cultural context and history, not least, Africa (Masolo 2010: 20). This is in stark contrast to 
colonising academics of the Western world such as G.W.F. Hegel, who, arguing from hearsay and conjecture, is on record for describing Africa as devoid of history and culture. He writes,

The African, in his undifferentiated and concentrated unity, has not yet succeeded in making this distinction between himself as an individual and his essential universality, so that he knows nothing of an absolute being [God or Law] which is other and higher than his own self (cited in Hamblet 2008: 138; also see Strauss 1976: 276).

But Hegel was not alone in this dehumanisation and distortion of African realities. Many Western anthropologists actually believed that Africa's history started with the advent of colonialism and Christianity. For example, whenever you studied the history of South Africa our standard history textbooks taught us that the history of South Africa started with the arrival of Jan van Riebeeck whilst that of Zimbabwe was said to have started with the arrival of Cecil John Rhodes and the Pioneer column when they invaded Matabeleland in 1890. In the realm of religion, the message that was disseminated by Western missionaries was that Africans did not have a religion, or that they were animists. This distortion was not only in the realm of culture, history and religion. Even the founder of psychodynamic theory, Sigmund Freud, in his book Totem and Taboo, advanced the theory that the morality of Africans was comparable to the behaviour of neurotics in Western societies. As he put it,

We can thus judge the so-called savage and semi-savage races; their psychic life assumes a peculiar interest for us, for we can recognize in their psychic life a well-preserved, early stage of our own development.

If this assumption is correct, a comparison of the 'Psychology of Primitive Races' as taught by folklore, with the psychology of the neurotic as it has become known through psychoanalysis, will reveal numerous points of correspondence and throw new light on subjects that are more or less familiar to us (Freud [1918] 1938: 80).

Obviously such writings were aimed at promoting the belief that Africans came late on the stage of human evolution. This was mainly based on the Western 
interpretation of Charles Darwin's theory of evolution. Ali Mazrui characterised this Western ethnocentricism as being part and parcel of the debiologisation of Darwin's theory whereby focus was shifted from a biological explanation of different cultures, to Western culture as the prototype of all world cultures. Thus he writes,

The shift from biological explanations of human backwardness to cultural explanations of the factor had important implications .... There is a quality almost of immutability, of being retarded, when a lack of development is attributed to hereditary characteristics within the race (Mazrui 1969: 92).

The Western ethnic interpretation of Darwin's theory of evolution somehow greatly distorted the African indigenous identity. For example, a world respected colonial academic, Jan Christian Smuts delivered a Rhodes lecture at Oxford about an African person in which he had the following to say,

This type [i.e., the African] has some wonderful characteristics. It has largely remained a child type, with a child psychology and outlook .... The African easily forgets past troubles and does not anticipate future troubles. This happy-go-lucky disposition is a great asset, but it also has its drawbacks. There is no inward incentive to improvement, there is no persistent effort in construction, and there is complete absorption in the present, its joys and sorrows .... No indigenous religion has been evolved, no literature, no art since the magnificent promise of the cavemen and the South African petroglyphist, no architechture since Zimbabwe (if that is African ...) (Smuts 1940: 37-38).

Apart from the dehumanisation of the indigenous African within such colonial writings, any form of scientific architecture and arts that were found among indigenous peoples were thus attributed to external origins.

By denying the fact that creativity existed among the indigenous peoples, early colonial scholars fostered seeds of misrecognition of the indigenous African as the legitimate producer of knowledge. Indigenous Africans were not only described as lacking in scientific discoveries, they were also frequently described as actually lacking in moral values. A colonial Polish anthropologist, Stanlva Andreski would go as far as to assert that indigenous Africans were pathological liars. As he put it, 
Concerning the African's lack of inhibition about telling lies - which forms one of the favourite topics for denigration among the expatriates - it is important to realise that the tribal customs not only do not enjoin telling truth to strangers, but even recommend dissimulations (Andreski 1968: 83).

Colonial conquest was not only about the annexation of foreign territories, rather it carried with it the imposition of Western knowledge systems and values that denigrated indigenous ones.

African indigenous knowledge systems thus denigrated as having nothing to contribute to human advancement in terms of civilisation and technological advancements, was indeed a European ethnic understanding of knowledge. Thus the indigenous African response to this European ethnic arrogance took two different approaches. The first approach was based on undermining the European self-acclaimed origins of human civilisation by asserting that the indigenous African pre-cololonial civilisations actually superseded European civilisation. Thus in this vein, it was argued that,

Ancestors of the Negro race drifted into the Nile Valley from Ethiopia, trekked down the river and finally established themselves in Egypt. By 3000 BC, there were already a highly civilised community (Chigwedere 1998: 208).

In such writings the implied argument is that European scholarship wrote history in a way that did not recognise the African contribution to human civilisation.

The second approach, was that scholars globally positioned Africa as the continent where all humanity originated from - being the 'cradle of humankind', not least South Africa. If Africa is indeed the cradle of humanity, it could also be considered as the cradle of human civilisation. There is a school of thought among anthropologists, archaeologists and historians that asserts that 'Africa before the European had had its own complex civilisations' (Mazrui 1986: 73). This school of thought not only asserts, but also glorifies the indigenous African cultural and historical achievements, creativity, personality and identity. It should be celebrated rather than denigrated - if not despised by European ethnic scholarship - and is something that indigenous Africans should take pride in, and continue to intellectualise. 


\section{On Indigenous Knowledge Systems and the Celebration of 'Primitivism'}

One of the main approaches to the intellectualisation of African indigenous knowledge systems, has taken the form of revisiting the previously colonially denigrated and condemned African traditional knowledge systems. Regarded as foundational to knowledge development and knowledge production, it is regarded as not only worthy of reconstruction, but also of preserving, and intellectualisation for purposes that address current world systems problems such as global warming. Some anthropologists such as Michael Gelfand, puts his finger on the issue, when he criticises Western cultural practices, for their inherent capitalist goals and objectives, and an appreciation of indigenous Shona cultural practices. He writes,

The materialistic philosophy of the West with its emphasis on accumulation seems not to be a matter of any concern [among the Shona]. In this environment man (sic) is more interested in pure living with people and his link with Nature, with the land, the water and his cattle. He seems to have found peace of mind in the quietude of nature, the silence of the hills, the rush of wind, the resilient trees in which the spirits of his ancestors hover near him and where he finds inspiration and feels free (Gelfand 1981: 76-77).

This quotation shows an appreciation of indigenous knowledge systems and modes of living in contrast to the Western capitalist modes of being that is mostly concerned with the idea of the endless accumulation of wealth. It is also an example of the growing appreciation of contemporary scholars, of indigenous knowledge systems, and, that we shall have to address our contemporary existential problems such as global warming, diseases and wars, from the ground up. Inherent in such arguments, is also an explicit statement or implicit assumption that the existential and environmental threats that the world is facing at present, has come about, due to their historical origins in Western 'civilisation'. For example, in his promotion of a certain appreciation of 'primitivism', Aidan Campbell asserts that the Western world is slowly awakening to the idea that there was something immensely valuable in the values and indigenous knowledge systems of the so-called primitive peoples. He avers, 
No longer is primitivism solely associated with atrocities and bloodletting. Whereas humanity used to be equated with civilisation, that is, with independence from nature, the meaning of humanity has been transformed into proximity to nature. Indeed, many of the problems currently associated with society - wars, corruption, repression, pollution - are ascribed to the fact that humanity has lost contact with nature. In other words, it is the overcivilised who are now held responsible for the savagery of the world (Campbell 1997:13-14).

Advocates of indigenous knowledge systems are thus sceptical about the assumptions about their knowledge(s) coming from Western 'civilisation'. Moreover, the appreciation of indigenous knowledge systems are also appreciative of the fact that the privileging of the 'primitive' is apparently serving certain emergent needs in Western societies that are emanating from a general prevailing sense of discontent with what was previously celebrated as civilisation (Prozesky 2009: 301; Bujo 2009). Campbell further elaborates on this trend of thought, when he says:

The prevailing mood that privileges a primitivist perspective helps offset any criticism directed against the system for failing to deliver the goods. Indeed, Western society is often indicted for being obsessed with consumption. A sanitised image of the African primitive serves as a role model to reinforce this message of limits preached at Western audiences. Primitivism celebrates weakness and underdevelopment as being more humane than the rugged entrepreneur of the 1980s or the racist thug. Articulating the standpoint of the primitive has become a mark of social sophistication that encompasses everyone from members of the British royal family ... (Campbell 1997: 15).

Through the celebration of the 'primitive', there is a global acceptance that indigenous knowledge systems are legitimate knowledge systems that serve people's wellbeing, and that they should be recognised as being endowed with something to contribute to the plurality of human existence. This global recognition of indigenous knowledge systems goes against the idea of privileging Western knowledge systems, a practice that dominated African societies and other non-African colonised societies. Lotte Hughes expressed this recognition as follows. 
In my experience, indigenous peoples have many admirable qualities that are sorely needed in today's world - including spirituality, egalitarianism, a sense of being grounded or centered, a lack of neurosis, wisdom, strength, usually a great sense of humor and perspective, too. They foresaw the global social and environmental crisis generations ago, and it's about time the rest of us paid attention to their vision and example (Hughes 2003: 8).

However, this mode of thought is contradicted by those scholars who conceptualise the current global processes as simply a manifestation of the imperial hegemony of Western knowledge systems and its cultural practices. This trend of thought is pivotal to the proponents of Euro-centric diffusionism. Amongst others, it is central to Theodore von Laue's argument, when he advanced the thesis that westernisation constituted a revolution of the whole world which is evolving towards westernisation. He writes,

For the first time in all human experience the world revolution of Westernization brought together, in inescapable intimate and virtually instant interaction, all the peoples of the world, regardless of their prior cultural evolution or their capacity - or incapacity - for peaceful coexistence .... Robbed of their past freedom to go their own ways politically and culturally, non-Western peoples were subjected to a world order that perpetuated or even deepened their helplessness. Henceforth equality could be attained only in terms imposed by the West (von Laue 1987: 3-4).

Eurocentric diffusionism sees other non-Western cultures as virtually impotent when it comes to contributing to global cultural, scientific and technical knowledge systems. Likewise, Linda Smith, is sceptical about the appreciation of indigenous knowledge systems in a global world that is dominated by America and the West. She observed,

The globalisation of knowledge and Western culture constantly reaffirms the West's view of itself as the centre of legitimate knowledge, the arbiter of what counts as knowledge and the source of civilised knowledge. This form of global knowledge is generally referred to as 'universal' knowledge (Smith 2006: 63). 
But the view of the dominance of the West in the creation and dissemination of knowledge is countered by other scholars who see an allinclusive or inclusionary approach to knowledge as an inescapable reality of the processes of globalisation. For example, Prozesky argued against the idea of disrespecting non-Western cultures in a globalised and multicultural world as follows.

Basing our ideas about right living only on Western ethics might have been the understanding a generation or two ago and earlier, before cultural diversity became as widespread as it is now .... What is no longer acceptable, either academically [and] ethically, is the assumption that the wider world of ethical philosophy beyond the West can simply be ignored (Prozesky 2007: 71-73).

In this way of thinking all cultures of the world, whether civilised or primitive have something to contribute to the generality of human existence. For this reason, indigenisation of knowledge through the promotion of indigenous knowledge systems is a quest for promoting a global inclusionary knowledge.

\section{Indigenisation of Knowledge as a Quest for Inclusionary Knowledge}

As shown in the preceding section, those who advocate the respect and cultivation of indigenous knowledges, or primitivism, have argued for the prioritisation of indigenous knowledge systems for the protection of the world on the basis that these knowledge systems represent ideals of the development of humanity's relations with nature - humanity's 'proximity to nature' - and a variety of social and cultural values. So, even if African knowledge systems have been marginalised with regard to intellectualisation and knowledge production, as well as appropriate knowledge dissemination, it is vitally important that they be centrally included in knowledge production systems. For some, this is an ethical issue. Referring to Africa's positioning in this regard, Amina Mama says,

Africa is characterised as the region bearing the most negative consequences of globalisation, a reality that offers a critical vantage 
point well-attuned to the challenge of demystifying the global policy dictates currently dominating the global landscape (Mama 2007: 1).

The underlying reason behind Mama's claim that African scholars are busy demystifying global knowledge systems, is that African scholarship has not only been critical of how colonising knowledge has extracted knowledge from Africa - and to certain degrees continue to do this - but that they are at the forefront of identifying issues that should be the concern of scholars internationally. Mama though also criticises African scholars, saying that Africa's contribution to the global knowledge about itself has remained insignificant whilst Western scholars have monopolised knowledge about Africa. In this regard, African scholars are challenged to address this matter. African indigenous systems will remain globally excluded if they are not intellectualised and their knowledge(s) disseminated, by Africans themselves, those born within African cultures. If this does not happen, African scholars will be complicit in the hegemony of Western knowledge about itself; it will participate in 'the internationalisation of global hegemonic thought within African scholarships' which on several occasions manifest itself in the form of 'uncritical reliance on externally generated paradigms, concepts, and methodologies which simplify and homogenise Africa' (Mama 2007: 5). In the final analysis, the implication of Mama's observation is that African indigenous knowledge systems have remained monopolised by Western societies and the African scholars are challenged to address this issue constructively, despite, as Mama avers, the problem of the fact of Africa's precarious economic condition.

This latter point rightly assumes that sub-Saharan Africa has remained in a perpetual state of economic dependence, and that this may be the reason why African scholars have not come to the table to address this matter. The upshot is too, that, in the wide variety of research projects that scholars engage African indigenous knowledge systems and practices annually, many scholars and communities cannot participate on their own terms, beause of their economic dependencies - e.g. on donor funding from the USA and the European Union. Sometimes it is the donors who set the agenda on what should be researched and what knowledge disseminated. Any knowledge that is deemed prejudicial to the economic and political interests of the donor will not receive funding (Ake 1994: 17). Often, copyright too, goes to the donors who fund the research (Murove 2013). Obviously such a practice perpetuates the 
culture of exclusion in the African academic terrain by virtue of the persistent reality of economic dependency.

Rather than such an approach, we should collectively rather seek cultural interdependencies. Indigenous knowledge intellectualisation and knowledge development, should be sought interdependently, and collaboratively. Such an approach, an approach that relies on the indigenous cultural and knowledge lenses of the people on the ground, implies that there is no single culture that can claim to having the monopoly of true knowledge. It also implies the recognition that universal knowledge systems are at base, contextual, and ethnic in orientation. This is to counter the practice, through which Western colonial knowledge systems got it completely wrong (Masolo 2010: 21).

For us to be in the position to deny the claims to colonising universalism and return to inclusionality, we have to insist that all human knowledge is relative or context specific. Christopher Miller is well nuanced on the idea of the relativity of knowledge when he said,

... the failure to relativize one's own beliefs is more dangerous than the failure to stay within them. Unless the Western critic attempts to suspend - to hold in at least temporary abeyance - the systematic criteria and judgments that emanate from Western culture, ethnocentricism will persist forever. There is no way to break down intellectual imperialism if Western disciplines are not reconceived as 'local knowledge' (Miller 1990: 65).

A critical aspect of Miller's observation is that when a particular ethnic group universalises its own particular experiences of being in the world, the end result is that of failure to recognise the diversity of human experiences which are usually integral to all human existence. Those scholars who see Western knowledge as a universal of universals are most likely prone to judge those who do not subscribe to such an epistemic orientation as ethnically biased. The notion of the promotion of the cultural relativity of human knowledge, debunks the notion of universal truths that are context neutral, and at the same time enable us to maintain that all knowledge is context specific and is produced, and configured within a particular cultural setting. The other implication is that knowledge is ethnic by origin, whether in orientation, or in application. This claim is also central to the very concept of indigenous 
knowledge systems because the salient presumption in this concept is that all knowledge is ethnic in its primordial mode (Russell 1992: 168; Masolo 2010: 26-34).

To talk about inclusionality and ethnicity in this argument, seems to be contradictory. But this should not be the case. Rather, the recognition of the production, as well as the orientation and use of knowledge from independent existences in fact enrich one's experience of being in a world characterised by diversity in human experience. This idea is well articulated by Jürgen Habermas as follows.

The overwhelming evidence of the fragmentation of multicultural societies and the Babylonian confusion of tongues in an overly complex global society seems to impel us toward holistic conceptions of language and contextualist conceptions of worldviews that make us sceptical about universalist claims, whether cognitive or normative. The complex and still unsettled debate about rationality also has implications, of course, for the concepts of a 'politics of recognition' (Habermas 1994: 121).

Central to Habermas' argument for an inclusionary approach to knowledge, is that one has to embrace diversity, and give recognition to each of the multiplicity of worldviews that constitutes the diversity. Each cultural practice and mode of conceptualising the world has a contribution to make to the world of diversity.

Furthermore, in the context of the globalisation of the world, and its continuous shrinking due to world-wide communication systems, our quest for inclusionality and the recognition of diversity and cultural relativism that is entailed in multiculturalism, curtails the hegemony of those knowledges that are being produced from economically powerful systems and institutions. It will also prevent the predetermining of the discourse about the knowledge that has to be deemed as universally acceptable.

Within a world that is also ever more sensitised to multiculturalism, the issue of inclusivity is also an ethical one. Here the normative ethical approach to knowledge requires the valuing and appreciation of the reality of diversity engendered within the multiplicity of our human existence. Whilst there is diversity in our cultural modes of being in the world, and modes of knowledge, different cultures may articulate their experiences differently, 
whilst articulating the same meaning about the same phenomenon. For instance, the now notorious perceptions of African religions of being articulated with nature, and therefore superstitious - as we for instance find in the totemism advanced by James Frazer (Frazer 1910: 3) - today, appears to be a spiritual phenomenon that should be supported, in the face of the denigration and exploitation of nature for capitalist gains. Today, perceptions of the oneness of humanity and nature, have become the source of the convergence of thought amongst all the peoples of the world, at least those concerned for the long-time wellbeing of the planet. For instance, Ali Mazrui says:

Of course, the oneness of nature which Darwin was trying to sell to the scholarly world was not of the same kind as the oneness of nature which underlay many totemic belief systems. But the great breakthrough here in nature convergence was the very postulate of a natural unity, even if the basis of that unity differed as between Darwinism and totemism. A whole movement has got under way in more recent times, manifesting a deep and sincere ecophilia (Mazrui 1976: 43).

Here the point which is being made by Mazrui is that different cultural modes of thought converged on the idea that human beings share the same origins with all other natural species.

Another example where thoughts from different cultural backgrounds can converge can be discerned from Southern Africa where the dominant approach to ethics is usually articulated in the concept of Ubuntu - a Nguni word that means humanness. The main presumption within this ethic is that one's humanity is recognised by recognising the humanity of others, of being a human being in community. In this regard, human existence and ultimate wellbeing are understood in terms of relatedness within the community. In this regard to be thus recognised as endowed with Ubuntu one must be compasssionate, generous, kind, considerate, and caring, just to mention a few of the virtues related to Ubuntu. Similarly, among the peoples of Western cultures, this concept of a human person is well echoed in the ethical traditions such as Virtue ethics, and Utilitarianism, whereby a concern for the wellbeing of the community is highly prized. In the face of the diversity inherent in human ethical traditions, there are sometimes more commonalities than differences. 


\section{Conclusion}

In this article I argued for the appreciation, and intellectualisation, of indigenous knowledge systems discourse in Africa, with specific reference to the aftermath of colonising knowledges, as well as the fact of the globalised multicultural world, which is dominated by Western knowledge systems. The challenge for indigenisation discourse in post-colonial Africa, is to bring to the fore the importance of inclusionary knowledge on a world scale. In this regard I have advanced three arguments which support the idea that the indigenisation discourse in a globalised world should be seen as an attempt to accompany the realities of globalisation and multiculturalism.

Firstly, I argued that the very idea of the indigenisation of knowledge has to be seen as an acknowledgement of the fact that all knowledge is contextual. The idea that knowledge is contextual implies that we should come to terms with the context where this knowledge is created. Social context plays a critical role because it determines the type of knowledge that is created and disseminated. Failure to realise the context specificity of knowledge can only lead to the creation of distorted knowledge as was the case during the era of colonialism in Africa.

Secondly, the African post-colonial response to colonial knowledge production, was countered by the glorification of the indigenous personality, as well as the promotion of processes that glorify that which was denigrated by European colonial scholarship. Called 'primitivism' by some, the enhancement of indigenous knowledges stand in stark contrast to the usual academic tendency of privileging Western knowledge systems. In the celebration of primitivism there is a tacit advocacy for an authentic knowledge that is rooted in context, as it promotes human wellbeing in harmony with the environment and nature, as that type of knowledge that is inclusionary.

Thirdly, the argument for the intellectualisation and indigenisation of knowledge as a quest for inclusionary knowledge, came in the form of an argument which said that in our contemporary globalised world, African scholarship has been marginalised in the creation and dissemination of knowledge - not least about Africa itself. The creation and dissemination of knowledge has remained monopolised by Western scholars, also because of the poor economic resources for researches from within the continent. Rather than participating in the production of the Western hegemony of knowledge, African scholars should engage the intellectualisation and production of local 
knowledges, even when there is a dearth of resources. In a multicultural and globalised world, the normative ethical approach to knowledge requires the appreciation of the diverse modes of knowing within our human existence.

\section{References}

Ake, C. 1994. Academic Freedom and Material Base. In M.D.M. Mamdani (ed.): Academic Freedom in Africa. Oxford: Codeseria Book Series, Oxford University Press.

Andreski, S. 1968. The African Predicament: A Study in the Pathology of Modernisation. London: Michael Joseph.

Blaut, J. 1993. The Colonizer's Model of the World: Geographical Diffusionism and Eurocentric History. London: Macmillan.

Campbell, A. 1997. Western Primitivism: African Ethnicity. A Study in Cultural Relations. London: Cassell.

Chigwedere, A. 1998. The Roots of the Bantu. Harare: Jongwe Printing and Publishing Co.

Dixon, V. 1976. Worldviews and Research Methodology. In L.M. Dixon, V.J.

Nobels \& W. King (eds.): African Philosophy: Assumptions and Paradigms for Research on Black Persons. Los Angeles: Fanon Centre Publications.

Frazer, J.G. 1910. Totemism and Exogamy. London: Macmillan Press. Freud, S. [1918] 1938. Totem and Taboo: Some Points of Agreement between the Mental Lives of Savages and Neurotics. London: Routledge.

Gelfand, M. 1981. Ukama: Reflections on Shona and Western Cultures in Zimbabwe. Gweru: Mambo Press.

Hamblet, W. 2008. Savage Constructions: The Myth of African Savagery. Lanham: Lexington Books.

Habermas, J. 1994. Struggles for Recognition in the Democratic Constitutional

State. In Taylor, C. (ed.): Multiculturalism: Examining the Politics of Recognition. Princeton: Princeton University Press.

Hughes, L. 2003. No-Nonsense Guide to Indigenous Peoples. London: Verso. Mama, A. 2007. Is it Ethical to Study Africa? Preliminary Thoughts on Scholarship and Freedom. African Studies Review 50,1: 1-26.

Masolo, D. 2010. Self and Community in a Changing World. Bloomington and Indianapolis: Indiana University Press. 
Mazrui, A. 1969. Violence and Thought: Essays on Social Tensions in Africa. London: Longmans.

Mazrui, A. 1976. A World Federation of Cultures: An African Perspective. New York: The Free Press.

Mazrui, A. 1986. The Africans: A Triple Heritage. London: BBC Publications. Mazrui, A. 1999. Trends in Philosophy and Science in Africa. In Mazrui, A. \&

C. Wondji (eds.): General History of Africa. VIII: Africa since 1935. California: James Currey. Available at:

https://www.sahistory.org.za/sites/default/files/file\%20uploads\%20/gene ral_history_africa_viii.pdf

Mill, J. 1960. Utilitarianism: Liberty and Representative Government. Londong: J.M. Dent \& Sons Ltd.

Miller, C. 1990. Theories of Africans: Francophone Literature and Anthropology in Africa. Chicago: University of Chicago Press.

Murove, M. 2014. Academic Freedom and the African Experience. (Unpublished Paper.).

Prozesky, M. 2007. Conscience: Ethical Intelligence for Global Well-Being. Pietermaritzburg: University of KwaZulu-Natal Press.

Russell, B. 1992. Human Society in Ethics and Politics. London: Routledge.

Smith, L. 1999. Decolonizing Methodologies: Research and Indigenous Peoples. London \& New York: Zed Books Ltd.

Smuts, J. 1940. Greater South Africa: Plans for a Better World. Johannesburg: Truth Legion.

Strauss-Levi, C. 1976. The Savage Mind. London: William \& Norgate. Taylor, C. 1994. The Politics of Recognition. In Gutmann, A. (ed.): Multiculturalism: Examining the Politics of Recognition. Princeton University Press.

Van Binsbirgen, W. \& R. van Dijk (eds.) (2004). Situating Globality: African Agency in the Appropriation of Culture. Leiden: Brill.

Von Laue, T. 1987. The World Revolution of Westernisation: The Twentieth Century in Global Perspective. Oxford: Oxford University Press.

Munyaradzi Felix Murove Ethics Studies School of Religion, Philosophy and Classics University of KwaZulu-Natal murovem@ukzn.ac.za 